\title{
Importance of endothelial nitric oxide synthase for the hypothermic protection of lungs against ischemia-reperfusion injury
}

Li Zhang, MD, Sanjeev Kumar, BS, Alexander Kaminski, MD, Cornelius Kasch, Christoph Sponholz, MD, Christof Stamm, MD, Yury Ladilov, PhD, and Gustav Steinhoff, MD

From the Department of Cardiac Surgery, University of Rostock, Rostock, Germany.

Supported by grant STE 495/6-1 of the Deutsche Forschungsgemeinschaft.

Received for publication Oct 19, 2005; revisions received Dec 12, 2005; accepted for publication Dec 16, 2005.

Address for reprints: Yury Ladilov, PhD, Department of Cardiac Surgery, University of Rostock, Schillingallee 35, 18057 Rostock, Germany (E-mail: yury.ladilov@ @med. uni-rostock.de).

J Thorac Cardiovasc Surg 2006;131:969-74

$0022-5223 / \$ 32.00$

Copyright $\odot 2006$ by The American Association for Thoracic Surgery

doi:10.1016/j.jtcvs.2005.12.033
Objectives: The hypothesis that the protective effects of mild hypothermia against the pulmonary ischemia-reperfusion injury are mediated by endothelial nitric oxide synthase was tested.

Methods: Endothelial nitric oxide synthase knock-out and wild-type mice were sham operated or underwent a 1-hour occlusion of the left pulmonary hilum, followed by 5 hours of reperfusion. Temperature in the left pleural cavity during ischemia was maintained at either $36^{\circ} \mathrm{C}$ (normothermia) or $32^{\circ} \mathrm{C}$ (hypothermia). Inflammatory response (myeloperoxidase activity), endothelial barrier function (extravasation of Evans blue-labeled albumin), and endothelial nitric oxide synthase expression and phosphorylation were determined at the end of reperfusion.

Results: After normothermic ischemia both strains had a similar mortality (wildtype, $22.9 \%$; knock-out, $15.4 \%$ ), which was completely abolished by hypothermia. Endothelial barrier function was disturbed after normothermic ischemia in both wild-type and knock-out mice. Mild hypothermia significantly reduced pulmonary Evans blue extravasation in wild-type mice, but not in knock-out mice. Myeloperoxidase activity increased after normothermic ischemia to the same degree in both strains. This response was significantly attenuated by hypothermia in wild-type mice, but not in knock-out mice. In wild-type mice, endothelial nitric oxide synthase expression and phosphorylation were higher after hypothermic ischemia than after normothermic ischemia. No effect of ischemia on expression of inducible nitric oxide synthase was found in wild-type or knock-out mice.

Conclusion: Hypothermic protection against pulmonary ischemia-reperfusion injury is dependent on endothelial nitric oxide synthase and is associated with increased expression and phosphorylation of endothelial nitric oxide synthase.

$\mathrm{P}$ ulmonary dysfunction after cardiopulmonary bypass or lung transplantation is a frequently observed phenomenon that is associated with lung ischemiareperfusion (I/R) injury. Among the main detrimental consequences of I/R are endothelial dysfunction and the inflammatory response. Release of nitric oxide (NO) may significantly modulate I/R injury. ${ }^{1}$ Numerous studies suggested that NO can exert both protective and deleterious effects depending on the amount and the source of NO production. At low concentrations, NO released by endothelial NO synthase (eNOS) is protective by preserving endothelial function and inhibiting the inflammatory response. However, higher concentrations of NO produced by inducible NO synthase (iNOS) can exacerbate reperfusion injury through formation of the toxic free radical peroxynitrite. ${ }^{2}$ During I/R, down-regulation of eNOS activity and up-regulation of iNOS has been described in several studies, ${ }^{3-5}$ and such alterations of the NO system are associated with endothelial dysfunction and proinflammatory reactions. ${ }^{1,6}$ 


\author{
Abbreviations and Acronyms \\ $\mathrm{EB}=$ Evans blue \\ eNOS $=$ endothelial nitric oxide synthase \\ iNOS $=$ inducible nitric oxide synthase \\ $\mathrm{nNOS}=$ neuronal nitric oxide synthase \\ $\mathrm{I} / \mathrm{R}=$ ischemia/reperfusion \\ $\mathrm{KO}=$ knock-out \\ $\mathrm{MPO}=$ myeloperoxidase \\ $\mathrm{NO}=$ nitric oxide \\ SEM $=$ standard error of the mean \\ WT $=$ wild-type
}

It has recently been reported that hypothermia can exert its protective effect against I/R injury by modulation of the NO system. Particularly, studies on brain ${ }^{7,8}$ and mesenteric ${ }^{9}$ tissue demonstrated the inhibition of iNOS/neuronal NOS (nNOS) expression and NO production by hypothermia during ischemia, leading to attenuation of the postischemic inflammatory response. ${ }^{7}$ Whether hypothermia produces similar effects on eNOS remains unclear. Using eNOS knockout (KO) mice, we have recently shown that eNOS is crucial in protection of lungs against $\mathrm{I} / \mathrm{R}$ injury by attenuation of leukocyte infiltration and adhesion molecule expression. ${ }^{10}$ In the present study, applying the same model, we tested whether eNOS plays a role in hypothermia-induced protection against $\mathrm{I} / \mathrm{R}$ injury of lungs.

\section{Material and Methods \\ Surgical Procedure}

All animal experiments were carried out in accordance with the guidelines of the local regulatory agencies and conformed with the "Guide for the Care and Use of Laboratory Animals" published by the National Institutes of Health (NIH Publication No. 85-23, revised 1996).

Six- to eight-week-old female wild-type (WT, $\mathrm{n}=68)$ mice (C57BL/6NCrl; Charles River, Sulzfeld, Germany) and eNOS knock-out (KO, $\mathrm{n}=50)$ mice (B6.129P2-Nos3; Charles River) were randomly divided into 4 groups: group I: WT, normothermic lung ischemia $(\mathrm{n}=35)$; group II: WT, hypothermic lung ischemia $(\mathrm{n}=25)$; group III: $\mathrm{KO}$, normothermic lung ischemia $(\mathrm{n}=19)$; group IV: KO, hypothermic lung ischemia $(\mathrm{n}=26)$. Five further animals of each species were sham-operated and 3 WT mice were used as positive controls by being given $10 \mathrm{mg} / \mathrm{kg}$ of intraperitoneal lipopolysacchrides from Escherichia coli for 24 hours to induce maximal proinflammatory stimulation.

Animals were anesthetized by intraperitoneal injection of $0.5 \mathrm{mg} / \mathrm{g}$ 2-2-2-tribromoethanol (Avertin; Sigma Chemical Company, St Louis, Mo). Orotracheal intubation was performed, and mechanical ventilation was initiated and maintained until the time of extubation. Inspiratory oxygen fraction was 0.3 and a rate of ventilation was 130 breaths/min with a maximal airway pressure of $12 \mathrm{~cm} \mathrm{H}_{2} \mathrm{O}$ and a positive-end expiratory pressure of $4 \mathrm{~cm} \mathrm{H}_{2} \mathrm{O}$ (SAR-830P small animal ventilator; IITC-Life Science, Woodland Hills, Calif). After subcutaneous injection of heparin (600 IU/kg), a left thoracotomy was performed. The left pulmonary hilum including bronchus, pulmonary artery, and pulmonary veins was occluded for 1 hour with a microsurgical clamp. During ischemia the skin incision was temporarily closed by sutures and the temperature in the left pleural cavity was monitored continuously by a thermometer probe inserted through the skin incision into the left pleural cavity. The temperature of ischemic lungs was adjusted with a heating device to either $36^{\circ} \mathrm{C}$ (normothermia) or $32^{\circ} \mathrm{C}$ (hypothermia), while the rectal temperature was always maintained at $36^{\circ} \mathrm{C}$ with a heating pad. On removal of the clamp, the left lung was reventilated. The chest was closed in layers followed by weaning from ventilation and extubation. After 5 hours of lung reperfusion, animals were humanely killed, and the left lungs were excised and processed for further analysis. In sham-operated animals, a thoracotomy was performed without lung ischemia.

\section{Western Blotting}

Frozen lung tissue was weighed and homogenized in ice-cold lysis buffer $(50 \mathrm{mmol} / \mathrm{L}$ Tris-HCl, $1 \mathrm{mmol} / \mathrm{L}$ ethylenediaminetetraacetic acid, $250 \mathrm{mmol} / \mathrm{L}$ sucrose, $20 \mathrm{mmol} / \mathrm{L}$ 3-[(3-cholamidopropyl) dimethyl-ammonio]-1-propanesulfonate, $20 \mathrm{mmol} / \mathrm{L}$ phenylmethanesulfonyl fluoride, $\mathrm{pH}$ 7.4). After centrifugation at $16,000 \mathrm{~g}$ for 15 minutes at $4^{\circ} \mathrm{C}$, the supernatant was used for Western blotting. Fifty micrograms of protein per lane were separated by sodium dodecyl sulfate-polyacrylamide gel electrophoresis using $10 \%$ gels. Equal loading of lines was confirmed by Coomassie blue staining. Gels were transferred to a nitrocellulose membrane (Hybond-ECL; GE Healthcare, Piscataway, NJ). The membranes were then blocked and incubated with the following primary antibodies overnight at $4^{\circ} \mathrm{C}$ : anti-eNOS (Calbiochem, EMD Biosciences, San Diego, Calif), anti-iNOS (BD Transduction Laboratories, Lexington, Ky), and anti-phosphorylated eNOS, specific to phosphorylated Ser-1177, (Calbiochem). Horseradish peroxidase-conjugated secondary antibody (goat anti-mouse immunoglobulin, Bio-Rad Microscience, Hercules, Calif) was used at 1:6,000 dilution. After being washed with TBS-Tween, proteins were detected with the use of opti-4CN Substrate (Bio-Rad). Optical densities of protein bands were normalized in each case to the density of $\beta$-actin band from the same sample and expressed in relative units.

\section{Endothelial Barrier Function}

Capillary permeability was evaluated by measuring extravasation of Evans blue (EB) dye in the lung tissue. EB binds to serum albumin and has been extensively used as a tracer for transcapillary flux of macromolecules. EB was slowly injected into the left internal jugular vein (30 mg/kg, dissolved in $200 \mu \mathrm{l}$ saline). Thirty minutes later the chest was opened and the lungs were perfused with 5 to $10 \mathrm{~mL}$ of phosphate buffer via a pulmonary arterial catheter to remove excess intravascular dye. Lungs were excised, homogenized, and incubated in 100\% formamide $(1 \mathrm{~mL}$ per 100 $\mathrm{mg}$ lung) at $37^{\circ} \mathrm{C}$ for 24 hours to extract $\mathrm{EB}$ dye. The concentration of EB dye extracted in formamide was analyzed by spectrophotometry at wavelengths of 620 and $740 \mathrm{~nm}$. The correction of optical densities (E) for contaminating heme pigments was calculated as described previously ${ }^{11}: \mathrm{E}_{620}$ (corrected) $=\mathrm{E}_{620}-(1.426 \times$ $\left.\mathrm{E}_{740}+0.03\right)$, and was expressed in arbitrary units. 
Evans Blue

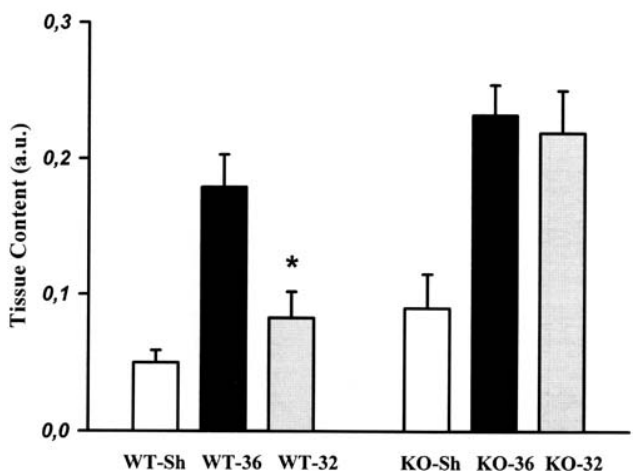

Figure 1. Effects of hypothermia on Evans blue content (arbitrary units [au]) in lungs subjected to $\mathbf{6 0}$ minutes of ischemia and $\mathbf{5}$ hours of reperfusion. Evans blue was estimated in WT and eNOS KO mice after sham ischemia (Sh) or after ischemia at $32^{\circ} \mathrm{C} \mathrm{(32)}$ or $36^{\circ} \mathrm{C}(36)$. Values are mean \pm SEM. $n=5$ to $7 ;{ }^{*} P=.01$ versus WT-36.

\section{Myeloperoxidase (MPO) Activity Assay}

Neutrophil infiltration in the lungs was assessed by measuring the activity of myeloperoxidase (MPO), an enzyme specific for granulocyte lysosomes. This assay has been found to be a more sensitive method for the detection of entrapped neutrophils than quantitative histology. ${ }^{12}$ We modified the method first described by Laight and associates. ${ }^{13}$ In brief, lungs were washed with phosphate buffer and homogenized by ultrasonicator for $10 \mathrm{sec}-$ onds in $1 \mathrm{~mL}$ of hexadecyl-trimethyl-ammoniumbromide (Sigma) buffer, followed by 3 freeze-and-thaw cycles. The tissue homogenate was incubated at $60^{\circ} \mathrm{C}$ for 2 hours to exclude nonthermoresistent peroxidases and centrifuged at $12,000 \mathrm{~g}$ for 10 minutes. Forty microliters of the supernatant was then allowed to react with $400 \mu \mathrm{L}$ of 3,3-5,5 tetramethylbenzidine (Sigma). Changes in extinction at a wavelength of $655 \mathrm{~nm}$ were measured by photometer over 3 minutes at 30-second intervals. MPO activity was expressed in units per gram of lung tissue. One unit of MPO activity was defined as an increase of optical density by 1.0 per minute.

\section{Statistical Analysis}

Data are presented as mean \pm SEM. Statistical analysis between groups was performed by 1-way analysis of variance followed by the Bonferroni post hoc test.

\section{Results}

\section{Mortality}

During 5 hours of reperfusion, mortality after normothermic $\left(36^{\circ} \mathrm{C}\right)$ ischemia was $22.9 \%$ in WT mice $(\mathrm{n}=8 / 35)$ and $15.4 \%$ in $\mathrm{KO}$ mice $(\mathrm{n}=3 / 19)$, which was not significantly different between the groups (the Fisher exact test). Mild hypothermia $\left(32^{\circ} \mathrm{C}\right)$ during ischemia completely abolished the postischemic mortality in both WT and KO mice ( $0 \%$ each). Similarly, no mortality was observed in sham-operated animals.
MPO-Activity

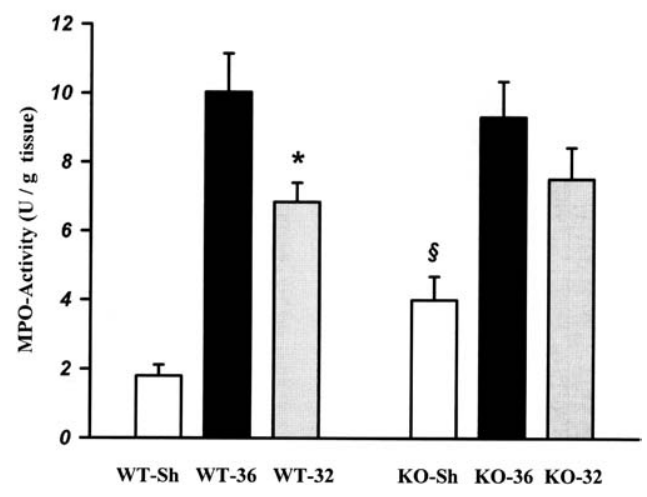

Figure 2. Effects of hypothermia on tissue MPO activity (units per gram tissue) in lungs subjected to $\mathbf{6 0}$ minutes of ischemia and 5 hours of reperfusion. MPO activity was estimated in WT and eNOS KO mice after sham ischemia (Sh) or after ischemia at $32^{\circ} \mathrm{C}$ (32) or $36^{\circ} \mathrm{C}(36)$. Values are mean \pm SEM. $n=5$ to $10 ;{ }^{*} P=.016$ versus WT-36; $\S P=.001$ versus WT-Sh.

\section{Endothelial Barrier Function}

In sham-operated animals EB tissue content did not differ significantly between WT and KO mice. One hour of normothermic ischemia followed by 5 hours of reperfusion dramatically increased EB content in injured lungs in both mouse types to the same degree (Figure 1). Mild intraischemic hypothermia demonstrated a marked protection of endothelial function in WT mice: EB content (arbitrary units) in injured lungs was $0.179 \pm 0.024(\mathrm{n}=6)$ after normothermic ischemia versus $0.083 \pm 0.019(\mathrm{n}=6 ; P=.01)$ after hypothermic ischemia. In contrast, hypothermia failed to preserve endothelial function in KO mice: similar EB content in lungs after normothermic and hypothermic ischemia was observed.

\section{Inflammatory Response}

Tissue MPO activity was used as a quantitative marker of inflammatory response to I/R-induced injury. ${ }^{12}$ It was slightly but significantly higher in sham-operated KO animals than in WT mice: MPO activity (units per gram tissue) was $4.0 \pm 0.68(\mathrm{n}=5)$ in $\mathrm{KO}$ mice versus $1.8 \pm 0.32(\mathrm{n}=$ $10)$ in WT mice $(P=.001)$. This finding is in line with previously described increased baseline rolling and endothelial adherence of leukocytes in eNOS KO mice. ${ }^{14}$ After normothermic ischemia, MPO activity was significantly elevated in both WT and KO mice in comparison with shamoperated animals (Figure 2). The inflammatory response was significantly attenuated by hypothermia during the ischemic period in WT mice: $10.0 \pm 1.1(\mathrm{n}=5)$ after normothermic ischemia versus $6.84 \pm 0.56(\mathrm{n}=6)$ after hypothermic ischemia $(P=.016)$. However, no significant effect of hypothermia on MPO activity was observed in KO mice. 
eNOS

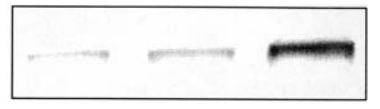

beta-actin

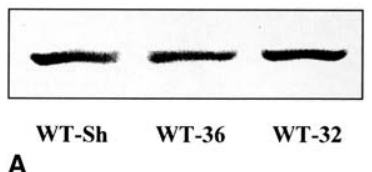

A

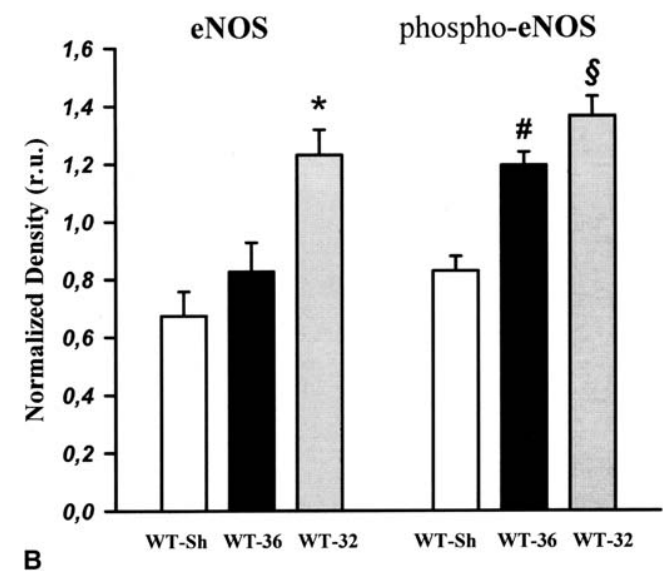

Figure 3. Expression of eNOS and phosphorylated eNOS (phospho-eNOS) in lungs subjected to 60 minutes of ischemia and 5 hours of reperfusion. (A, Western blots prepared from lungs of WT mice after sham ischemia (Sh) or after ischemia at $32^{\circ} \mathrm{C}(32)$ or $36^{\circ} \mathrm{C}$ (36). Data are representative from 6 independent experiments with similar results. B, Analysis of optical band density of eNOS and phospho-eNOS expressed as a ratio to $\beta$-actin band density (relative units). Values are mean \pm SEM. $n=6$. ${ }^{*} P=.01$ versus WT-Sh; $\# P<.001$ versus WT-Sh; $\$ P<.001$ versus WT-32 and $\boldsymbol{P}=.033$ versus WT-36.

\section{NOS Isoform Expression}

Protein expression of eNOS and iNOS after pulmonary I/R was analyzed by Western immunoblotting. In WT mice, normothermic ischemia followed by reperfusion did not significantly change eNOS protein expression (Figure 3), whereas reperfusion after hypothermic ischemia significantly increased expression of eNOS by approximately 2-fold $(P=.01)$. The further analysis of the phosphorylation status of eNOS at Ser-1177, which is critical for eNOS activation, revealed a significant increase of phosphorylated eNOS in WT mice after both normothermic and hypothermic ischemia in comparison with sham-operated animals. The increase of eNOS phosphorylation was, however, significantly higher $(P=.033)$ after hypothermic ischemia than after normothermic ischemia.

Because iNOS may also participate in postischemic tissue injury, ${ }^{2}$ the expression of this NOS isoform was
iNOS

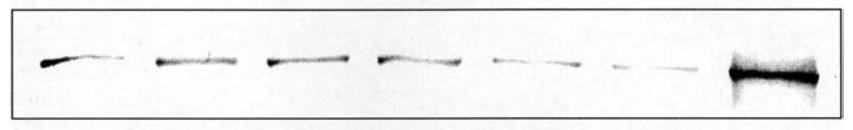

beta-actin

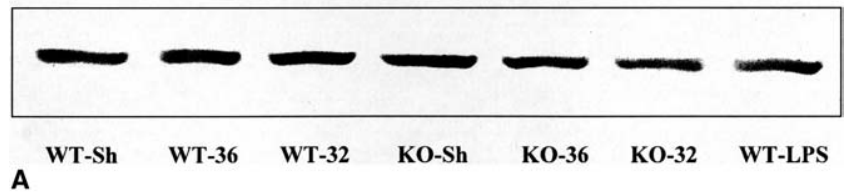

iNOS

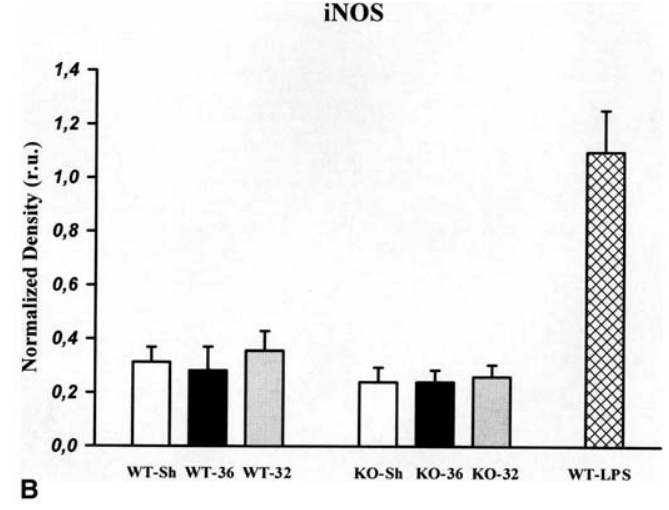

Figure 4. Expression of iNOS in lungs subjected to 60 minutes of ischemia and 5 hours of reperfusion. A, Representative Western blots prepared from lungs of WT and eNOS KO mice after sham ischemia (Sh) or after ischemia at $32^{\circ} \mathrm{C}(32)$ or $36^{\circ} \mathrm{C}(36)$. As a positive control, intraperitoneal treatment with $10 \mathrm{mg} / \mathrm{kg}$ lipopolysacchrides (LPS) from Escherichia coli for 24 hours was used. Data are representative from 3 to 4 independent experiments with similar results. B, Analysis of optical band density of iNOS expressed as a ratio to $\beta$-actin band density (relative units). Values are mean \pm SEM. $n=3$ to 4 .

also analyzed. Baseline expression of iNOS was detectable in sham-operated animals. However, no effects of $\mathrm{I} / \mathrm{R}$ in WT and KO mice on iNOS protein expression were observed (Figure 4). To exclude the false-negative results, animals were treated with $10 \mathrm{mg} / \mathrm{kg}$ lipopolysacchride from Escherichia coli, which resulted in a significant increase of iNOS expression 24 hours after treatment.

\section{Discussion}

The aim of this study was to test the importance of eNOS in intraischemic hypothermia-induced protection against $\mathrm{I} / \mathrm{R}$ lung injury. Using a transgenic eNOS KO mouse model, we found that the hypothermia-induced preservation of endothelial barrier function and attenuation of the postischemic inflammatory response were eNOS dependent. This protective effect of hypothermia was associated with significant 
up-regulation of the postischemic expression and phosphorylation of eNOS in the lungs.

Injury of the endothelium is a common consequence of an ischemic insult. During reperfusion, release of oxygen radicals and proinflammatory cytokines can additionally jeopardize endothelial function. ${ }^{15}$ In a previous study, ${ }^{10}$ we observed that the inflammatory response reached its peak 5 hours after ischemia. Similarly, in the present study, along with an increase of the MPO activity, the content of EB dye in lungs increased significantly after 1 hour of normothermic ischemia and 5 hours of reperfusion in both WT and $\mathrm{KO}$ mice, indicating a pronounced disturbance of endothelial integrity. Therefore, applying endothelial barrier function and inflammatory response as end points of assessment of the postischemic pulmonary injury, we analyzed the role of eNOS in the protective effect of hypothermia. For this purpose a mild hypothermia $\left(32^{\circ} \mathrm{C}\right)$ was chosen to minimize the side effects of hypothermic exposure. ${ }^{16}$ Such mild hypothermia seems also to be more applicable in the clinical setting. ${ }^{17}$

Several experimental and clinical studies have demonstrated the protective action of hypothermia against postischemic inflammatory response and endothelial function. ${ }^{7,18}$ In accordance with these reports, we found that intraischemic mild hypothermia dramatically attenuates lung injury and abolishes mortality during the reperfusion period. Within several mechanisms responsible for hypothermic protection during the period of ischemia, delays in the onset of irreversible cellular injury via reduction of the metabolic rate, attenuation of adenosine triphosphate depletion, and preservation of intracellular ion homeostasis were described. ${ }^{19}$ However, the finding of the present study that the beneficial effect of mild hypothermia during lung ischemia is dependent on the presence of eNOS and even associated with eNOS overexpression, to the best of our knowledge, has not been demonstrated before. Several studies have investigated the role of the NO system during I/R injury in brain and mesenteric tissues. ${ }^{7-9}$ It was found that the protective effect of intraischemic hypothermia was associated with suppression of iNOS/nNOS expression and NO release during reperfusion. The up-regulation of these NOS isoforms may lead to excessive NO release associated with production of peroxynitrite and aggravation of tissue injury. In rat lungs, Scumpia and colleagues ${ }^{20}$ also found that moderate hypothermia retarded iNOS transcription, which restricted endotoxemic lung injury. Our previous study did not support the roles of nNOS and iNOS pulmonary I/R injury. Similarly, in the present study, independent of temperature no effect of $\mathrm{I} / \mathrm{R}$ on iNOS expression was found. This finding excludes the role of the iNOS in hypothermic protection. The discrepancy with previous studies may result from differences in target organ (lungs vs brain ${ }^{7-9}$ ) or in injury model (I/R vs lipopolysaccharide treatment ${ }^{20}$ ). In contrast to iNOS, eNOS seems to play a substantial role in hypothermia-induced protection of lungs. Indeed, two lines of evidence demonstrate the importance of eNOS in the present study. First, hypothermia-induced protection against I/R injury was completely abolished in eNOS KO mice. Second, hypothermia was associated with postischemic up-regulation of eNOS.

There is increasing evidence indicating that eNOS plays an essential role in postischemic organ protection. Particularly, eNOS activity has been shown to be important for preservation of endothelial function and attenuation of postischemic inflammation in different tissues. ${ }^{1,2,4}$ Regarding lung tissue, only a few studies emphasized the function of eNOS in I/R injury. ${ }^{10,21-23}$ Our previous study suggested that up-regulation of eNOS attenuates endothelial cellleukocyte adhesion via suppression of vascular cell adhesion molecule expression. ${ }^{10}$ A significant up-regulation of eNOS was, however, observed only 24 hours after reperfusion. In the present study, with the temperature being lowered during ischemia, up-regulation of eNOS expression occurred as early as 5 hours after ischemia. Thus, the acceleration of eNOS expression might be one of the intrinsic mechanisms of hypothermia-induced protection against I/R injury. In accordance with this finding, Liu and cowork$\mathrm{ers}^{23}$ also demonstrated a marked increase of eNOS expression in rat lungs after hypothermic ischemia within 2 hours of reperfusion. How hypothermia may affect the eNOSexpression timing is still unclear. The eNOS expression is a function of the balance between the protein synthesis and degradation. The regulation of these processes is complex, and the precise analysis of the mechanisms involved in hypothermia-induced eNOS up-regulation was beyond the scope of the present study.

The biologic relevance of eNOS expression is highly dependent on posttranslational control of the enzyme activity. Phosphorylation of eNOS at Ser-1177 has been shown to be an essential step in eNOS activation, ${ }^{24}$ and increased phosphorylation of eNOS during reperfusion was demonstrated in several studies. ${ }^{25,26}$ In accordance with these observations, we found that I/R in WT mice increased eNOS phosphorylation, which was more pronounced after hypothermic ischemia. Although one may argue that increased phosphorylation of eNOS at Ser-1177 in the present study does not necessarily implicate eNOS activation, it nevertheless demonstrates the hypothermia-induced preservation of the phosphorylation-dependent regulation mechanism of eNOS activity.

\section{Conclusion}

In summary, applying the murine eNOS KO model, we have provided evidence that protection against pulmonary I/R injury by mild intraischemic hypothermia is eNOS dependent and is accompanied by up-regulation of eNOS expression and phosphorylation. Further analysis of this eNOSdependent mechanism of hypothermic protection could 
provide new strategies for better pulmonary preservation and prevention of I/R injury.

The technical help of C. Fahle is gratefully acknowledged. Part of this study was the part of the thesis of S. Kumar submitted in fulfillment of the requirements for the degree of Doctor of Philosophy at the Unversity of Rostock (Germany).

\section{References}

1. Vinten-Johansen J, Zhao ZQ, Nakamura M, Jordan JE, Ronson RS, Thourani $\mathrm{VH}$, et al. Nitric oxide and the vascular endothelium in myocardial ischemia-reperfusion injury. Ann NY Acad Sci. 1999;874:354-70.

2. Jugdutt BI. Nitric oxide and cardioprotection during ischemiareperfusion. Heart Fail Rev. 2002;7:391-405.

3. Giraldez RR, Panda A, Xia Y, Sanders SP, Zweier JL. Decreased nitricoxide synthase activity causes impaired endothelium-dependent relaxation in the postischemic heart. J Biol Chem. 1997;272:21420-46.

4. Muscari C, Bonafé F, Gamberini C, Giordano E, Tantini B, Fattori M, et al. Early preconditioning prevents the loss of endothelial nitric oxide synthase and enhances its activity in the ischemic/reperfused rat heart. Life Sci. 2004;74:1127-37.

5. Naito $Y$, Takagi T, Ichikawa H, Tomatsuri N, Kuroda M, Isozaki Y, et al. A novel potent inhibitor of inducible nitric oxide inhibitor, ONO-1714, reduces intestinal ischemia-reperfusion injury in rats. $\mathrm{Ni}$ tric Oxide. 2004;10:170-7.

6. Leindler L, Morschl E, Laszlo F, Mandi Y, Takacs T, Jarmai K, et al Importance of cytokines, nitric oxide, and apoptosis in the pathological process of necrotizing pancreatitis in rats. Pancreas. 2004;29:157-61.

7. Han HS, Qiao Y, Karabiyikoglu M, Giffard RG, Yenari MA. Influence of mild hypothermia on inducible nitric oxide synthase expression and reactive nitrogen production in experimental stroke and inflammation. J Neurosci. 2002;22:3921-8.

8. Karabiyikoglu M, Han HS, Yenari MA, Steinberg GK. Attenuation of nitric oxide synthase isoform expression by mild hypothermia after focal cerebral ischemia: variations depending on timing of cooling. J Neurosurg. 2003;98:1271-6.

9. Hassoun HT, Kozar RA, Kone BC, Safi HJ, Moore FA. Intraischemic hypothermia differentially modulates oxidative stress proteins during mesenteric ischemia/reperfusion. Surgery. 2002;132:369-76.

10. Kaminski A, Pohl CB, Sponholz C, Ma N, Stamm C, Vollmar B, et al. Up-regulation of endothelial nitric oxide synthase inhibits pulmonary leukocyte migration following lung ischemia-reperfusion in mice. Am J Pathol. 2004;164:2241-9.

11. Wang E, Ouellet N, Simard M, Fillion I, Bergeron Y, Beauchamp D, et al. Pulmonary and systemic host response to Streptococcus pneu- moniae and Klebsiella pneumoniae bacteremia in normal and immunosuppressed mice. Infect Immun. 2001;69:5294-304.

12. Goldblum SE, Wu KM, Jay M. Lung myeloperoxidase as a measure of pulmonary leukostasis in rabbits. $J$ Appl Physiol. 1985;59:1978-85.

13. Laight DW, Lad N, Woodward B, Waterfall JF. Assessment of myeloperoxidase activity in renal tissue after ischemia/reperfusion. Eur J Pharmacol. 1994;292:81-8.

14. Lefer DJ, Jones SP, Girod WG, Baines A, Grisham MB, Cockrell AS, et al. Leukocyte-endothelial cell interactions in nitric oxide synthasedeficient mice. Am J Physiol. 1999;276:H1943-50.

15. Tedgui A, Mallat Z. Anti-inflammatory mechanisms in the vascular wall. Circ Res. 2001;88:877-87.

16. Tisherman SA. Hypothermia and injury. Curr Opin Crit Care. 2004; 10:512-9.

17. Bell TE, Kongable GL, Steinberg GK. Mild hypothermia: an alternative to deep hypothermia for achieving neuroprotection. J Cardiovasc Nurs. 1998;13:34-44.

18. Zar HA, Lancaster JR. Mild hypothermia protects against postischemic hepatic endothelial injury and decreases the formation of reactive oxygen species. Redox Rep. 2000;5:303-10.

19. Jahania MS, Sanchez JA, Narayan P, Lasley RD, Mentzer RM. Heart preservation for transplantation: principles and strategies. Ann Thorac Surg. 1999;68:1983-7.

20. Scumpia PO, Sarcia PJ, DeMarco VG, Stevens BR, Skimming JW. Hypothermia attenuates iNOS, CAT-1, CAT-2, and nitric oxide expression in lungs of endotoxemic rats. Am J Physiol Lung Cell Mol Physiol. 2002;283:L1231-8.

21. Suda T, Mora BN, D'Ovidio F, Cooper JA, Hiratsuka M, Zhang W, et al. Endothelial nitric oxide synthase function in pig lung after chronic pulmonary artery obstruction. Am J Respir Crit Care Med. 2000;162:1429-34.

22. Suda T, Mora BN, D'Ovidio F, Cooper JA, Hiratsuka M, Zhang W, et al. In vivo adenovirus-mediated endothelial nitric oxide synthase gene transfer ameliorates lung allograft ischemia-reperfusion injury. J Thorac Cardiovasc Surg. 2000;119:297-304.

23. Liu M, Tremblay L, Cassivi SD, Bai XH, Mourgeon E, Pierre AF, et al. Alterations of nitric oxide synthase expression and activity during rat lung transplantation. Am J Physiol Lung Cell Mol Physiol. 2000;278:L1071-81.

24. Michell BJ, Griffiths JE, Mitchelhill KI, Rodriguez-Crespo I, Tiganis $\mathrm{T}$, Bozinovski S, et al. The Akt kinase signals directly to endothelial nitric oxide synthase. Curr Biol. 1999;9:845-8.

25. Wolfrum S, Dendorfer A, Schutt M, Weidtmann B, Heep A, Tempel $\mathrm{K}$, et al. Simvastatin acutely reduces myocardial reperfusion injury in vivo by activating the phosphatidylinositide 3-kinase/Akt pathway. J Cardiovasc Pharmacol. 2004;44:348-55.

26. Osuka K, Watanabe Y, Usuda N, Nakazawa A, Tokuda M, Yoshida J. Modification of endothelial NO synthase through protein phosphorylation after forebrain cerebral ischemia/reperfusion. Stroke. 2004;35:2582-6. 